\title{
Tabuada Legal: um jogo sério para o ensino de multiplicações ${ }^{1}$
}

\author{
Andréa Cardoso, Astride G. C. Giraldello, Nalva Ap. M. Batista \\ Instituto de Ciências Exatas \\ Universidade Federal de Alfenas (UNIFAL-MG) Alfenas - MG - Brasil \\ andreac74@uol.com.br, \{tidegiraldello, nalvaalf\}@hotmail.com
}

\begin{abstract}
This paper presents the conception, development and validation of a serious game geared for multiplication, which has as purpose to motivate the student/gamer in the search for strategies that will assist in solving mental calculations with agility.
\end{abstract}

Resumo. Este trabalho apresenta a concepção, desenvolvimento e validação de um jogo sério voltado para a multiplicação, que tem como propósito motivar o aluno/jogador na busca por estratégias que o auxiliem na resolução de cálculos mentais com agilidade.

\section{Introdução}

De acordo com os Parâmetros Curriculares Nacionais (Brasil, 1997), os jogos constituem uma forma interessante de propor problemas ao permitirem que sejam apresentados de modo atrativo e favorecendo a criatividade na elaboração de estratégias de resolução e busca de soluções.

Os jogos são uma opção quando o objetivo é tornar as aulas de matemática mais interessantes e motivadoras no momento da retomada de conceitos ainda não consolidados. Em particular, as operações básicas da aritmética e seus algoritmos, estudadas nas séries iniciais do ensino fundamental, são pilares para o conhecimento matemático mais complexo. Porém não é raro encontrar estudantes que, no final do ensino médio, ainda não desenvolveram as habilidades necessárias em relação aos conceitos. Assim a utilização de jogos, que favoreçam a retomada e a consolidação desses conceitos, é alternativa a ser considerada.

Souza Jr. (2012) evidencia o despreparo do professor especialista, da disciplina de matemática nas séries finais do ensino fundamental e no ensino médio, em relação ao ensino das operações básicas da Aritmética. Muitas vezes, o professor de Matemática não foi preparado, em sua formação inicial ou continuada, para auxiliar o aprendiz no desenvolvimento das habilidades ainda não consolidadas de resolução de problemas envolvendo multiplicação e divisão de números inteiros.

Assim, os jogos digitais são recursos didáticos com características que podem trazer benefícios ao processo de ensino-aprendizagem, com efeito motivador, facilitador

\footnotetext{
${ }^{1} \mathrm{O}$ presente trabalho foi realizado com apoio financeiro do Programa Institucional de Bolsa de Iniciação à Docência (PIBID), da Coordenação de Aperfeiçoamento de Pessoal de Nível Superior (CAPES), Brasil e da Fundação de Amparo a Pesquisa do Estado de Minas Gerais (FAPEMIG).
} 
do aprendizado, desenvolvimento de habilidades cognitivas e aprendizado por descobertas, como descritos por Savi e Ulbricht (2008). Entretanto, ao buscar recursos que o auxiliem nesta tarefa, uma das dificuldades enfrentadas pelo professor é a ausência de materiais específicos para o ensino de aritmética, principalmente ao se referir aos jogos sérios.

Por outro lado, para que haja o desenvolvimento e a produção deste tipo de material didático, é necessário um conjunto de procedimentos para que o jogo se torne um recurso educativo efetivo.

Este trabalho apresenta o jogo sério "Tabuada Legal", avaliado e validado, cujo objetivo é a consolidação da operação de multiplicação de números naturais, com foco no calculo mental, antecipação de resultados e propriedades da operação de multiplicação, para estudantes das séries finais do ensino fundamental que ainda não consolidaram estratégias de multiplicação de números naturais. O jogo oferece atributos capazes de motivar e desenvolver habilidades tais como: multiplicar números naturais por meio de estratégias próprias, relacionar números e desenvolver estratégias de verificação e adequação de resultados através do cálculo mental. O tema do trabalho foi oportunizado a partir de observação das dificuldades dos estudantes de escolas públicas durante aplicações de atividades vinculadas ao Programa Institucional de Bolsa de Iniciação à Docência (PIBID), e à demanda por ferramentas motivadoras para as aulas de matemática. A avaliação do jogo foi realizada, junto a professores em formação e estudantes do segundo ciclo do ensino fundamental, baseada na metodologia RETAIN, relevância, incorporação, transferência, adaptação, imersão e naturalização, que de acordo com Luciano e Oliveira (2012), foi elaborada com o intuito de auxiliar pesquisadores, desenvolvedores e educadores nos processos de criação e avaliação de Jogos Sérios.

\section{Revisão de Literatura}

As operações básicas são conceitos de matemática que, em primeiro momento, não desperta grande preocupação, mas que pode acarretar dificuldades futuras. De acordo com Zatti, Agranionih e Enricone (2010), muitas das dificuldades relacionadas a este conteúdo podem ser atribuídas a não compreensão do algoritmo ou às dificuldades de atenção e/ou de memorização. A importância das operações básicas se evidencia por estarem presentes nos currículos escolares desde a primeira série do ensino fundamental até o final do ensino médio.

Diante destes fatos, professores buscam priorizar a construção do conhecimento trabalhando atividades que despertem o interesse e a motivação dos alunos, assim os jogos se tornam uma alternativa de desenvolvimento de capacidades e benefícios favoráveis à construção do conhecimento que são classificados por Teixeira, Sá e Fernandes (2006), em quatro categorias: físicas, desenvolvimento motor; intelectuais, habilidades como memória, concentração, abstração e raciocínio; sociais, aprendizado e assimilação de regras; didáticos, teorias educacionais.

O jogo desperta nos indivíduos a capacidade de socialização, cooperação e a competição, além de ser um instrumento de difusão sociocultural. Para Kistemann Júnior (2011), o jogo pode ser entendido "como um paralelismo entre o mundo real e o mundo imaginário que pode ser construído durante e a partir de atividade lúdica, que traduz uma representação do mundo sociocultural em que se insere a criança". 
Através da visualização e experimentação de conceitos, uma metodologia baseada em jogos visa aumentar a interação, produzir, explorar e exercitar o conhecimento. Porém, é importante ressaltar que o uso de jogos em metodologias de ensino requer empenho por parte dos professores, pois existem pontos positivos e negativos na utilização de jogos no ensino. Sendo assim, os professores devem ser críticos e objetivos ao utilizarem esta ferramenta em suas aulas. O planejamento e o desenvolvimento de uma aula utilizando jogos envolvem várias etapas, entre elas a pesquisa, a definição de objetivos e o conteúdo a ser explorado, que são de fundamental importância para a obtenção de resultados positivos, uma vez que "o jogo pelo jogo", sem direcionamento para o aprendizado e sem que seu potencial seja explorado de forma adequada, pode se transformar em uma atividade fracassada do ponto de vista do ensino-aprendizagem.

Apesar das diversas possibilidades de aprendizado, que tanto os jogos relacionados ao ensino quanto os recursos computacionais propiciam, para os professores ainda são uma novidade e muitas vezes não são aproveitados de forma adequada. A necessidade de uma formação continuada por parte dos professores é apontada pelos Parâmetros Curriculares Nacionais (Brasil, 1997), e isto se mostra evidente uma vez que fica claro o contraste entre o tradicional e o novo devido à falta de preparação profissional e planejamento educacional. Os jogos, muitas vezes, não são potencialmente explorados pelos professores, e muitas vezes, simplesmente são deixados de lado. Fortuna e Bittencourt (2003) consideram que no conhecimento adquirido pelos professores, em sua formação ou em leituras relacionadas ao assunto, predomina uma visão pronta e acabada a respeito de aprender e jogar, na qual os jogos são utilizados sem crítica ou simplesmente não são utilizados.

Pensando nas possibilidades favoráveis, provenientes do uso dos jogos, é conveniente aliá-los à educação matemática. Pensando nos problemas relacionados com a aprendizagem de Matemática, que são enfrentados em sala de aula, e na necessidade de propostas pedagógicas que sejam capazes de complementar os processos de ensino e aprendizagem, os jogos digitais se tornam uma possível alternativa na busca por propostas pedagógicas que sejam capazes de complementar o processo de ensino e aprendizagem sendo ao mesmo tempo uma atividade motivadora para o aprendiz. Entretanto, o tema ainda é pouco investigado. Pietruchinski e colaboradores (2011) realizaram uma pesquisa nos anais do Simpósio Brasileiro de Informática na Educação (SBIE) abrangendo o período de 2001 a 2010, e concluem que o número de publicações sobre o assunto jogos no ensino ainda é pouco difundido.

A utilização dos jogos digitais como complemento para o ensino propicia vantagens, tais como sons, cores e movimentos, que podem se tornar um atrativo aos alunos. Além disso, o uso de jogos como ferramenta de ensino e como mecanismo de aderência de conceitos e desenvolvimento de habilidades vem ganhando destaque e importância, como afirma Campos et al. (2011).

Um jogo digital deve apresentar aspectos positivos para o desenvolvimento e aquisição do conhecimento e, de acordo com Gladcheff, Oliveira e Silva (2001), para a sua utilização, é preciso considerar suas características formais, se há o desenvolvimento da lógica, do raciocínio claro, objetivo, coerente e criativo do aluno, e os aspectos relacionados ao conteúdo, se a temática é atraente para a realidade de vida do aluno. Neste sentido, surge o conceito de jogos sérios definidos por Michael e Chen 
(2006) como um jogo no qual o aprendizado, em suas diversas formas, é o principal objetivo, e não o entretenimento. O conceito de jogo sério foi concebido inicialmente para teste e treinamento, mas atualmente também é utilizado como ferramenta de ensino, devido a sua abordagem estar diretamente centrada em conteúdos específicos.

A metodologia RETAIN foi criada para avaliar a forma em que o conteúdo específico está imerso e incorporado no contexto do jogo, se há transferência de conhecimentos prévios e adquiridos e se há a automatização destes conhecimentos. Ela avalia as características de jogos digitais com relação a seis aspectos fundamentais: relevância, incorporação, transferência, adaptação, imersão e naturalização. Com base nos trabalhos de Luciano e Oliveira (2012) e Gunter, Kenny e Vick (2008), os aspectos da metodologia RETAIN são definidos como: i) relevância onde os materiais de aprendizagem, oferecidos pelo jogo devem despertar o interesse e demonstrar a importância do conteúdo abordado de forma relevante para os alunos e sua aprendizagem; ii) incorporação, o conteúdo educacional e o contexto de fantasia precisam estar relacionados e, para o bom funcionamento do conjunto aprendizagem e jogabilidade é preciso haver uma integração do primeiro para que se torne intrínseco ao outro; iii) transferência, o conhecimento prévio que será utilizado e a utilização dos conhecimentos adquiridos com o uso do jogo, para o processo de aprendizagem, a transferência e a aplicação destes conhecimentos são de fundamental importância; iv) adaptação é o resultado entre os processos de assimilação (interpretação de conhecimentos baseados em conhecimentos anteriores) e acomodação (alteração ou criação de novos conhecimentos) que implica em uma mudança de comportamento, ou seja, reutilização e reprodução dos conhecimentos adquiridos; v) imersão é a atratividade e a motivação que o jogo propicia onde a participação do jogador deve acontecer de forma intelectual e ativa no contexto do jogo; vi) naturalização relacionase com o desenvolvimento da automaticidade e o conhecimento adquirido é enraizado como um modo natural de pensar.

\section{Características do jogo "Tabuada Legal"}

O objetivo do jogo "Tabuada Legal" é motivar o aluno a criar estratégias para que a partir de resultados conhecidos seja capaz de encontrar novos resultados para a multiplicação de números naturais, possibilitando ao estudante entretenimento $\mathrm{e}$ aprendizagem.

No ambiente do jogo o aluno define passos e planeja suas ações, sendo ele personagem principal e atuando de maneira ativa o tempo todo, uma vez que o jogo exige planejamento para alcançar o objetivo proposto.

Para tanto o jogo oferece um conjunto de atrativos visuais e sonoros. Na tela há dois tipos de atores canhões-lançadores e sólidos geométricos numerados, que desempenham papéis distintos dentro de um cenário que vai se alternando no decorrer do jogo. A função dos canhões-lançadores é lançar os sólidos geométricos numerados aleatoriamente de modo a se chocarem para executar a operação de multiplicação. Estes sólidos se movimentam de forma aleatória colidindo entre si e com as paredes da tela. Aos números entre zero e nove estão associados representações planas de sólidos geométricos personalizados. Por exemplo, ao zero está associado um toro, uma esfera representa o número um, o três é representado por um tetraedro e os demais números 
estão associados a outros sólidos geométricos. Ao iniciar o jogo aparece uma tela contendo as instruções, conforme mostra a figura 1, à esquerda.

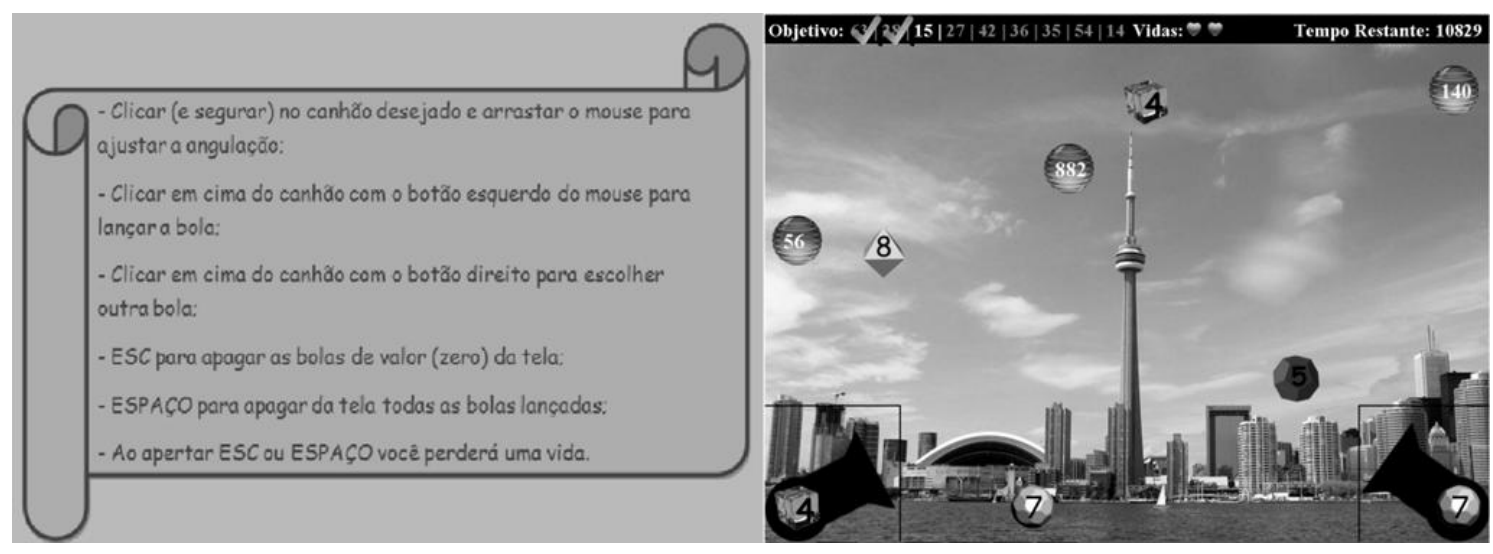

Figura 1. À esquerda: Tela Inicial contendo as instruções do jogo; À direita: Cenário do jogo.

$\mathrm{Na}$ parte superior da tela aparece um display contendo os resultados que deverão ser construídos a partir das multiplicações. Estes resultados vão sendo substituídos de acordo com os acertos. Também aparecem neste display o número de vidas e o tempo restante para conclusão do jogo. A figura 1, à direita, ilustra uma das telas do jogo.

O jogador controla a direção dos canhões-lançadores e os disparos são efetuados com o mouse para que os sólidos numerados se choquem adequadamente e seus valores sejam multiplicados para atingir o objetivo do jogo. Para que isto aconteça o jogador deve antecipar o resultado da multiplicação entre os sólidos que estão na tela e o próximo sólido a ser lançado. O jogo tem um tempo total de quatro minutos.

O jogo apresenta alguns obstáculos, um deles é o lançamento do sólido com valor numérico zero, pois toda multiplicação por zero resulta em zero. Outro obstáculo é quando os resultados das multiplicações atingem seu valor máximo, que é determinado de forma aleatória, pois à medida que se acumulam na tela dificultam as jogadas. Para ultrapassar estes obstáculos, o jogador conta com a opção de eliminar os zeros ou os sólidos em excesso, porém esta opção lhe custa uma vida, das três vidas iniciais.

Ao atingir todos os nove objetivos propostos, é apresentada a pontuação de acordo com o tempo restante. Sendo assim, é necessário que este jogador concilie raciocínio rápido, precisão nos cálculos mentais e agilidade no teclado para obter a maior pontuação possível.

\section{Metodologia}

O jogo foi projetado no Game Editor, ferramenta multimídia de desenvolvimento de jogos em duas dimensões (2D) com uma interface simples e intuitiva. Porém este editor possui limitações que impediram melhorias no mesmo. Assim optou-se por programar o jogo em Java, por ser uma linguagem de programação orientada a objetos e portável a todas as plataformas e sistemas operacionais. Para isso foi utilizado o Net Beans, que é um ambiente de desenvolvimento integrado gratuito e de código aberto para desenvolvedores de software em linguagem Java, entre outros. 
Na elaboração das imagens foi utilizado o Gimp para a edição e manipulação do cenário. O Gimp é um software livre, que permite a edição de imagens e criação de animações, é útil tanto para amadores como para profissionais por possuir uma linguagem simples e comandos em português.

Foram realizadas pesquisas visando obter materiais didáticos produzidos para o ensino da multiplicação. A pesquisa inicial, em uma página de busca da internet, objetivou simular o caminho que o professor trilharia na busca por jogos, que pudessem ser utilizados em suas aulas, sobre o assunto de multiplicação de números naturais. Também foram efetuadas buscas em repositórios de Objetos de Aprendizagem como o Banco Internacional de Objetos Educacionais (BIOE), a Rede Interativa Virtual de Educação (RIVED) e a Coletânea de Entidades de Suporte ao uso de Tecnologia na Aprendizagem (CESTA).

Por outro lado, foi realizada outra pesquisa objetivando a busca de artigos científicos que enfatizem o desenvolvimento de jogos na área de matemática e do conteúdo específico de multiplicação. Esta pesquisa foi realizada nos artigos publicados nos anais do Simpósio Brasileiro de Informática na Educação (SBIE), Workshop de Informática na Escola (WIE) e no periódico Revista Brasileira de Informática na Educação (RBIE), de 2001 a 2012, e buscou por "jogos na educação", "jogos na educação matemática" e "jogos envolvendo multiplicação" usando como palavras-chave "jogos, matemática e game”.

A metodologia RETAIN foi utilizada para a avaliação do jogo, a partir da qual foram elaborados três questionários. O primeiro questionário foi aplicado à 25 professores em formação que atuam em escolas públicas como bolsistas de Iniciação à Docência junto ao professor de matemática em exercício, e o dois outros questionários destinaram-se a alunos do segundo ciclo do ensino fundamental. O objetivo do primeiro questionário foi realizar a avaliação dos professores, após a experiência com o jogo, abrangendo questões relacionadas à experiência em sala de aula, à experiência com o uso de jogos educativos e especificamente ao potencial pedagógico do jogo "Tabuada Legal". Os questionários 2 e 3 , foram aplicados à estudantes do sexto ano e nono ano do ensino fundamental. O questionário 2 foi aplicado a toda turma, sem contato com o jogo, e teve como objetivo avaliar o conhecimento e a relação afetiva dos estudantes em relação à tabuada. O questionário 3 foi aplicado a 12 estudantes, selecionados das turmas participantes da pesquisa, que foram convidados a utilizar o jogo e a responder as questões após o contato com o jogo, objetivando a avaliação do jogo propriamente dito, a aprendizagem e a motivação decorrente da utilização deste. O critério de seleção destes estudantes teve por base os resultados do questionário 2 de modo que fossem escolhidos alunos com e sem dificuldade com a tabuada.

Por fim foi realizado um estudo de caso em sete alunos, dentre os doze que responderam os questionários 2 e 3 , selecionados a partir de observações das respostas dos alunos que classificaram como bom o seu relacionamento com a tabuada, contudo apresentaram dificuldades nas resoluções das multiplicações.

\section{Resultados}

A pesquisa realizada na página de busca da internet com as palavras-chave "Jogos educativos multiplicação", apontou 195.000 resultados dos quais 106 foram verificados. Com esta pesquisa foram encontrados 56 jogos de multiplicação com interfaces 
diferentes, porém seguindo um mesmo formato onde o jogador insere resultados de multiplicações pré-determinadas.

A busca por multiplicação na categoria de animação/simulação em português efetuada no BIOE resultou em 20 objetos, destes 13 são animações ou simulações que abordam o tema multiplicação de vetores ou matrizes, expressões numéricas, produtos notáveis, mínimo múltiplo comum ou cálculo com polinômios, que não interessam para este trabalho. Um deles é uma animação de resolução de problemas, 2 são jogos de perguntas e respostas e 4 são jogos envolvendo a operação de multiplicação de números. Dos quatro jogos encontrados um deles envolve apenas a multiplicação por 10. A tabela 1 apresenta os três jogos encontrados na busca no BIOE.

Tabela 1. Jogos digitais envolvendo a multiplicação, disponíveis no BIOE.

\begin{tabular}{|l|l|l|}
\hline \multicolumn{1}{|c|}{ Nome } & \multicolumn{1}{|c|}{ Objetivo } & \multicolumn{1}{c|}{ Descrição } \\
\hline $\begin{array}{l}\text { Memória da } \\
\text { Tabuada }\end{array}$ & Exercitar a tabuada & $\begin{array}{l}\text { É um jogo de memória no qual as peças são a } \\
\text { multiplicação de uma tabuada escolhida e sua } \\
\text { respectiva resposta }\end{array}$ \\
\hline Muro Numérico & $\begin{array}{l}\text { Trabalhar operações com } \\
\text { números naturais }\end{array}$ & $\begin{array}{l}\text { Apresenta um modelo de muro com números. O } \\
\text { usuário deve decidir se as operações que deram } \\
\text { origem a estes números são de adição ou de } \\
\text { multiplicação. Uma vez decidido o usuário efetua esta } \\
\text { operação em um novo muro proposto pelo objeto }\end{array}$ \\
\hline Aritmética 2.02 & $\begin{array}{l}\text { Estimular o cálculo mental } \\
\text { e permitir a visualização } \\
\text { das operações em uma } \\
\text { tabela }\end{array}$ & $\begin{array}{l}\text { Apresenta um jogo em que o aluno tem o auxílio de } \\
\text { uma tabela para realizar as operações de } \\
\text { multiplicação, divisão e fatoração de Números } \\
\text { Naturais }\end{array}$ \\
\hline
\end{tabular}

No repositório CESTA está disponibilizado apenas um objeto de aprendizagem sobre Matemática para o desenvolvimento de noção de quantidades numéricas para crianças, enquanto o RIVED não apresenta resultados para o tema multiplicação.

A partir das pesquisas realizadas é possível concluir que o professor ao buscar por jogos que o auxiliem nas dificuldades relacionadas à tabuada, vai encontrar vários jogos em que o aluno-jogador irá apenas representar resultados sem uma interação ativa com o jogo. De acordo com o resultado do questionário 1, nas questões referentes ao uso de jogos em sala de aula, 76\% dos entrevistados concordam que jogos são estratégias de ensino e apoiam seu uso. Contudo esta relevância não se mostra evidente nas publicações relacionadas ao assunto, uma vez que ainda é irrisório o número de artigos publicados sobre o assunto. A pesquisa aponta que cerca de $7 \%$ do total de publicações do SBIE, WIE e RBIE são relacionados a jogos em geral, apenas 1\% relacionados a conteúdos matemáticos, e especificamente sobre multiplicações não foram encontrados resultados.

O questionário 1, aplicado a professores em formação, aponta que há uma defasagem em relação ao conhecimento sobre operações básicas e a sua importância para a aquisição de novos conteúdos matemáticos. Com isso nota-se a crescente necessidade de recursos alternativos para a consolidação das habilidades dos estudantes em relação às operações básicas da aritmética. Neste questionário, em relação ao jogo, 
os professores participantes da pesquisa apontam que o fator sorte não está diretamente relacionado com o êxito do jogador.

No questionário 2, aplicado aos alunos do ensino fundamental, nas questões referente ao relacionamento com a escola, matemática e tabuada, conclui-se que as turmas de sexto ano possui um bom relacionamento com a escola e que há uma tendência à indiferença quando se trata da matemática, em específico da tabuada. Já as turmas de nono ano apresentam aversão à matemática. Esta mudança de comportamento coletivo em relação à matemática pode ser explicada pelas dificuldades nesta disciplina, devido principalmente às deficiências pré-existentes que vão se agravando no decorrer do ensino fundamental. Um exemplo disto é o conceito de multiplicação, que por não estar consolidado deixa de ser uma ferramenta para aquisição de novos conhecimentos. Isto é confirmado na análise das respostas ao questionário 2 que aponta a existência de alunos com dificuldades com a tabuada.

A partir do questionário 3, aplicado aos alunos do ensino fundamental após o jogo, é possível concluir que a opinião dos alunos em relação a matemática e a tabuada passou de indiferente para bom relacionamento. Nas questões sobre o entendimento das regras e o interesse pelo jogo, os estudantes apontaram resultados favoráveis e ao serem questionados se jogariam novamente, $100 \%$ dos alunos responderam de forma afirmativa.

Em geral, os alunos não apresentaram dificuldade para jogar ou para manipular o mouse e estabeleceram algumas estratégias tais como o lançamento do zero para eliminar os sólidos que atingirem valores elevados ou optando por perder vidas para recomeçar a fase.

A partir da metodologia RETAIN, quanto à relevância, o jogo "Tabuada Legal", desperta o interesse para a aprendizagem da tabuada, como apontado pela análise dos dados obtidos no questionário 1 e 3 , e, de acordo com os professores, o conteúdo multiplicação é abordado de forma relevante. Em relação à incorporação, tanto professores quanto estudantes consideraram a interface do jogo atrativa, e a facilidade no entendimento das regras e os conceitos apresentados durante a atividade se apresentam de forma integrada. A transferência, especificamente para o estudante, deuse quando ele utilizou alguns conhecimentos sobre multiplicação para definir estratégias e alcançar os objetivos do jogo. Referente à imersão, tanto alunos quanto professores consideraram que o jogo possui fatores atrativos e motivacionais, em especial os alunos questionaram a possibilidade de terem o jogo "Tabuada Legal" em suas casas.

$\mathrm{O}$ aspecto adaptação da metodologia RETAIN requer maior atenção uma vez que, para que ocorra uma mudança efetiva de comportamento se faz necessário novas aplicações. De acordo com o estudo de caso realizado com sete estudantes, a análise das respostas e a observação no momento da aplicação do questionário revelam que estes realizam a operação de multiplicação entre dois números naturais com um algarismo utilizando os dedos ou riscos no papel e que conhecem o algoritmo da multiplicação e o utilizam quando necessitam realizar multiplicações de números com mais de um algarismo. Assim, necessitaram de bastante tempo para realizar as operações indicadas no questionário 2. Já no questionário 3 , após a utilização do jogo, houve clara intenção de simular uma situação em que os alunos fossem obrigados a realizar estimativas e cálculos mentais, restringindo o tempo para responderem o questionário, o índice de acertos do grupo estudado apresentou ligeira queda, o que era esperado visto que, os 
processos de assimilação e acomodação ainda não se concretizaram. Também, para o aspecto naturalização, serão necessárias novas aplicações para conclusões efetivas, uma vez que o desenvolvimento da automaticidade é um processo gradativo e diferenciado para cada indivíduo.

É possível concluir que o jogo alcançou seu objetivo, pois nas opiniões dos alunos em relação à afirmação "Não gostei do jogo porque não sei tabuada!", a análise que se faz é que mesmo aqueles que não têm facilidade com a tabuada responderam que gostaram do jogo, respondendo de forma positiva às afirmações "Jogando eu me senti mais estimulado a aprender tabuada!" e "Jogando eu entendi melhor a tabuada!".

\section{Considerações Finais}

Diante do número reduzido de estudo sobre as contribuições da utilização de jogos no ensino de matemática básica, este trabalho apresenta a proposta de inserção de um jogo relacionado à operação de multiplicação de números naturais. Discute a avaliação do mesmo e as contribuições para a motivação do estudante em relação à tabuada.

De acordo com a metodologia RETAIN utilizada, avalia-se que o jogo "Tabuada Legal" apresenta recursos atrativos que estimulam o aluno a desenvolver estratégias para efetuar cálculos mentais com agilidade, utilizando conhecimentos prévios e aplicando novos conhecimentos, participando de forma ativa do jogo. Como complemento de ensino, o jogo apresenta vantagens, pois visa aumentar a interação, produzir, explorar e exercitar o conhecimento. De modo geral, o jogo apresenta regras compreensíveis, de fácil manuseio e estimula o aprendizado de matemática pelo fato do jogador ser impelido a jogar diversas vezes para superar sua pontuação.

Como trabalhos futuros, serão incrementadas ao jogo novas fases contendo as operações de adição, subtração e divisão e pretende-se disponibilizá-lo gratuitamente na web. Para a avaliação final dos aspectos de adaptação e naturalização, referentes à metodologia RETAIN, serão realizadas aplicações sistemáticas em alunos do ensino fundamental, além de introduzir tal jogo como recurso educacional para ser utilizado em sala de aula.

Neste contexto surge a necessidade de novas propostas de ensino das operações básicas e para atender a esta necessidade as aplicações de jogos digitais em sala de aula podem proporcionar aos professores de matemática a oportunidade de retomada de conceitos, amenizar problemas, além de possibilitar condições para que desperte a motivação para o aprendizado.

\section{Referências}

Brasil. (1997) Parâmetros Curriculares Nacionais: Matemática, MEC/SEF.

Campos, A. M. C. et al. (2011) "Um jogo voltado à prática de gerenciamento de projetos", In: SIMPÓSIO BRASILEIRO DE INFORMÁTICA NA EDUCAÇÃO, XXII. Aracaju. Anais... Aracaju: SBIE, p. 534-537.

Fortuna, T. R. e Bittencourt, A. D. da S. (2003) "Jogos e educação: o que pensam os educadores", Psicopedagogia, 20(63), p. 234-242.

Gladcheff, A. P., Oliveira, V. B. e Silva, D. M. (2001) "O software Educacional e a Psicopedagogia no Ensino de Matemática direcionado ao Ensino Fundamental", 
Revista Brasileira de Informática na Educação, Disponível em: http://www.brie.org/pub/index.php/rbie/article/view/2246/2008. Acesso em: julho 2013.

Gunter, G. A., Kenny, R. F. e Vick, E. H. (2008) "Taking educational games seriously: using the RETAIN model to design endogenous fantasy into standalone educational games", Education Tech Research Dev. 56:511-537.

Luciano, A. P. C. e Oliveira, L. C. (2012) "Metodologia RETAIN para avaliação de sérios games aplicado ao jogo Eletrocity", Enect, Realize. Disponível em: http://editorarealize.com.br/revistas/enect/trabalhos/Poster_838.pdf. Acesso em: Julho 2013.

Kistemann Jr, M. A. (2011) "Brincar e jogar: enlaces teóricos e metodológicos no campo da educação matemática", Bolema, v.24, n. 38, p. 297-302.

Michael, D. R. e Chen, S. L. (2006) "Serious Games: Games That Educate, Train, and Inform”, Muska \& Lipman/Premier-Trade, p. 17.

Pietruchinski, M, H. et al. (2011) "Os jogos educativos no contexto do SBIE: uma revisão sistemática de literatura", In: SIMPÓSIO BRASILEIRO DE INFORMÁTICA NA EDUCAÇÃO, XXII, Anais... Aracajú-SE, p. 476-485.

Savi, R. e Ulbricht, V. R. (2008) "Jogos digitais educacionais: benefícios e desafios", Novas tecnologias na educação. Disponível em: http://seer.ufrgs.br/ renote/article/view/14405/8310.pdf. Acesso em: Janeiro 2013.

Souza Jr, J. C. (2012) "Relações entre a matemática científica e a matemática escolar no curso de formação inicial e atividades do PIBID”, In: Gomes, C. e Felício, H. M. S. (Orgs.). Caminhos para docência: o PIBID em foco. Oikos, p. 109-122.

Teixeira, J. S. F., Sá, E. J. V. e Fernandes, C. T. (2006) "Proposta de repositório inteligente para jogos cooperativos educacionais", In: SIMPÓSIO BRASILEIRO DE INFORMÁTICA NA EDUCAÇÃO, XVII, Anais... Brasília - DF, p. 511-718.

Zatti, F., Agranionih, N. T. e Enricone, J. R. B. (2010) “Aprendizagem matemática: desvendando dificuldades de cálculo dos alunos”, Perspectiva, v. 34, n. 128, p. 115132. 